\title{
Vulvar Melanoma: Molecular Characteristics, Diagnosis, Surgical Management, and Medical Treatment
}

\author{
Christoph Wohlmuth ${ }^{1}$ (D) - Iris Wohlmuth-Wieser ${ }^{2,3}$
}

Accepted: 26 May 2021 / Published online: 14 June 2021

(c) The Author(s) 2021

\begin{abstract}
Ten percent of all women have pigmented vulvar lesions. Fortunately, most of these are benign but $1 \%$ of all melanomas in women affect the vulva. While the mortality rate of cutaneous melanoma has dropped by $7 \%$ annually during the last 5 years, the prognosis of vulvar melanoma remains dismal: the 5-year overall survival rate is $47 \%$ compared with $92 \%$ for cutaneous melanoma. The current evidence suggests that this likely results from a combination of delayed diagnosis and different tumor biology, treatment strategies, and treatment response. Although many landmark trials on checkpoint inhibitors included mucosal and vulvar melanomas, the results were often not reported separately. Post-hoc analyses indicate overall response rates between 19 and $37 \%$ for checkpoint inhibitors. A recently published retrospective study on vulvar melanomas suggests an objective response in $33.3 \%$ with a similar safety profile to cutaneous melanoma. Tyrosine kinase inhibitors may be considered in recurrent disease if a $c$-KIT mutation is present.
\end{abstract}

\section{Key Points}

Compared with skin melanomas, vulvar melanomas are associated with a poor prognosis resulting from delayed diagnosis and different tumor biology, treatment strategies, and treatment response.

Novel treatment modalities include checkpoint inhibitors and targeted therapies and recent evidence shows that these are also effective in vulvar melanomas.

Vulvar melanomas have a different tumor biology with frequent $c$-KIT mutations, which provides an additional therapeutic target in recurrent disease.
Christoph Wohlmuth

christoph.wohlmuth@outlook.com

1 Department of Obstetrics and Gynecology, Paracelsus Medical University, Muellner Hauptstrasse 48, 5020 Salzburg, Austria

2 Department of Dermatology and Allergology, Paracelsus Medical University, Salzburg, Austria

3 Division of Dermatology, Department of Medicine, University of Toronto, Toronto, ON, Canada

\section{Introduction}

One in $41(2.4 \%)$ women will develop a malignant melanoma at some point during their life, making it the sixth most common cancer in women in the USA [1]. Vulvar melanomas (VMs) account for $1 \%$ of all melanomas in women and 5\% of all vulvar malignancies [2]. The majority of VMs are diagnosed in postmenopausal women, the median age at diagnosis is 68 years, but VMs have also been reported in children [2-7]. Strikingly, up to $10 \%$ of women have pigmented vulvar lesions $[8,9]$. Obviously, the majority of these are benign, but in view of the advanced stage and melanoma size at diagnosis and associated poor prognosis, there appears to be room for improvement in terms of early detection and treatment initiation. While the overall mortality rate of cutaneous melanoma has dropped by $7 \%$ annually during the last 5 years, this did not apply for VMs: for all stages combined, the 5-year overall survival rate for cutaneous melanoma is $92 \%$, compared with only $47 \%$ in VM; and there was no significant improvement over time [1,2]. These somber numbers may in part be explained by the delayed diagnosis compared with cutaneous melanomas. A recent US population-based study of 1863 women has shown that $38 \%$ of women with staged VM had advanced disease at the time of diagnosis with regional involvement and/or distant metastases. The mean size of the primary tumor at 
diagnosis was $31 \mathrm{~mm}$ and more than $46 \%$ had a Breslow's thickness $>2 \mathrm{~mm}$ [2]. This puts them at very high risk and large single-center series suggest that $52-63 \%$ of non-metastatic patients will eventually develop distant metastases [10-12]. The advanced stage at diagnosis may in part be explained by the location itself with potentially lower selfawareness, social awareness, and public awareness and the fact that most early-stage VMs are oligosymptomatic or asymptomatic [11, 13-15]. However, an analysis of the Dutch cancer registry has shown that even if matched for sex, age, tumor ulceration status, Breslow thickness, lymph node status, and distant metastases, VMs have a significantly worse prognosis compared with cutaneous melanomas [16]. This could be attributable to a different tumor biology and treatment approach or response. The latter is especially critical because of the lack of specific treatment guidelines for vulvovaginal melanomas, which in turn may increase treatment heterogeneity.

This comprehensive review aims to raise awareness among medical professionals and to provide up-to-date evidence on the molecular characteristics and the diagnosis and treatment of VMs, including surgery and medical therapy.

\section{Cancerogenesis and Molecular Biology of VM}

By definition, melanomas are cancers arising from melanocytes. The pathogenesis of VM remains largely unknown. Unlike cutaneous melanomas, VMs are unrelated to chronic sun exposure and damage from ultraviolet light. Chronic dermatoses such as lichen sclerosus have been discussed as potential risk factors based on findings from a populationbased study, but this warrants validation in larger scaled and prospective studies [17, 18].

Molecular characterization of VMs may shed more light on the carcinogenesis. Table 1 provides an overview of mutations in VMs summarizing previously published studies, where the location "vulva" was explicitly stated. The mitogen-associated protein kinase pathway is a signaling pathway that is commonly activated in malignant melanomas. The $c$-KIT gene encodes KIT (CD117), which is a class III transmembrane receptor tyrosine kinase and is expressed in a variety of cells $[19,20]$. While $c$-KIT mutations are rare in cutaneous melanomas [21,22], 21.6\% of women with VMs harbor a $c$-KIT mutation. The high rate of $c$-KIT mutations appears to be characteristic for VMs,

Table 1 Overview of molecular characteristics in malignant VMs

\begin{tabular}{|c|c|c|c|c|}
\hline Study, year & $\mathrm{VM}(n)$ & $B R A F, \%(n)$ & $N R A S, \%(n)$ & $c-K I T, \%(n)$ \\
\hline Edwards (2004) [115] & 8 & $0 \%(0 / 8)$ & n.a. & n.a. \\
\hline Cohen (2004) [116] & 8 & $0 \%(0 / 8)$ & n.a. & n.a. \\
\hline Wong (2005) [117] & 3 & $33.3 \%(1 / 3)$ & $0 \%(0 / 3)$ & n.a. \\
\hline Torres-Cabala (2009) [118] & 11 & n.a. & n.a. & $27.3 \%(3 / 11)$ \\
\hline Handolias (2010) [119] & 5 & n.a. & n.a. & $40.0 \%(2 / 5)$ \\
\hline Omholt (2011) [24] & 23 & $8.7 \%(2 / 23)$ & $0 \%(0 / 23)$ & $34.8 \%(8 / 23)$ \\
\hline Abu-Abed (2012) [120] & 17 & n.a. & n.a. & $5.9 \%(1 / 17)$ \\
\hline Aulmann (2014) [121] & 50 & $0 \%(0 / 39)$ & $11.9 \%(5 / 42)$ & $17.9 \%(7 / 39)$ \\
\hline Rouzbahman (2015) [30] & 13 & $7.7 \%(1 / 13)$ & $23.1 \%(3 / 13)$ & $23.1 \%(3 / 13)$ \\
\hline Pappa (2015) [122] & 10 & $10.0 \%(1 / 10)$ & $0 \%(0 / 10)$ & $0 \%(0 / 10)$ \\
\hline Tseng (2015) [34] & 12 & $0 \%(0 / 12)$ & $25.0 \%(3 / 12)$ & $16.7 \%(2 / 12)$ \\
\hline Yelamos (2016) [123] & 11 & $0 \%(0 / 11)$ & $0 \%(0 / 11)$ & $27.3 \%(3 / 11)$ \\
\hline Saleh (2017) [37] & 13 & $0 \%(0 / 13)$ & $7.7 \%(1 / 13)$ & $30.8 \%(4 / 13)$ \\
\hline Udager (2017) [124] & 19 & $0 \%(0 / 19)$ & $5.3 \%(1 / 19)$ & $15.8 \%(3 / 19)$ \\
\hline Hou (2017) [23] & 37 & $27.3 \%(9 / 33)$ & $0 \%(0 / 19)$ & $26.5 \%(9 / 34)$ \\
\hline Wylomanski (2018) [125] & 15 & $33.3 \%(5 / 15)$ & $6.7 \%(1 / 15)$ & $6.7 \%(1 / 15)$ \\
\hline Shi (2019) [126] & 4 & $0 \%(0 / 4)$ & $50.0 \%(2 / 4)$ & $25.0 \%(1 / 4)$ \\
\hline Wohlmuth (2020) [11] & 28 & $8.0 \%(2 / 25)$ & $13.3 \%(2 / 15)$ & $13.6 \%(3 / 22)$ \\
\hline Zarei (2020) [25] & 20 & $0 \%(0 / 20)$ & $20.0 \%(4 / 20)$ & $40.0 \%(8 / 20)$ \\
\hline Studies combined & 307 & $8.2 \%(21 / 256)$ & $10.2 \%(22 / 216)$ & $21.6 \%(58 / 268)$ \\
\hline
\end{tabular}

Summary of molecular characteristics of VMs from previously published studies evaluating melanoma mutations, where the vulvar location was specified. Single case reports were not included

$B R A F$ v-raf murine sarcoma viral oncogene homolog B1 mutations, $c$-KIT tyrosine-protein kinase Kit mutations, $n$ number, $n . a$. not assessed, $N R A S$ neuroblastoma RAS viral oncogene mutations, $V M s$ vulvar melanomas 
which also distinguishes them from vaginal melanomas. In one of the largest series, Hou et al. noted that $c$-KIT was the only molecular marker of interest that varied significantly between vulvar and vaginal sites, with $27 \%$ of vulvar samples harboring the mutation compared with only $8 \%$ of vaginal samples [23]. Similarly, Omholt et al. reported eight $c$-KIT mutations in 23 women with VM vs no mutations in seven women with vaginal melanomas [24]. No difference in the mutational profile between the hair-bearing and glabrous skin of the vulva appears to be present [25]. KIT activates downstream signaling cascades of the Ras/Raf/MEK/ERK pathway, a key regulator of melanoma cell regulation [26]. The most common $c$-KIT mutation in VMs is the L576P substitution accounting for $26.2 \%$ (Fig. 1A). This mutation is located on exon 11 and affects the juxta-membrane domain of KIT, promoting dimerization of the protein and its constitutive activation [21]. W557R accounted for $11.9 \%$ and is also located in the juxta-membrane domain on exon 11. K642E, which accounted for another $16.7 \%$, lies within the tyrosine kinase domain 1 on exon 13 , and results in constitutive phosphorylation of KIT and activation of downstream signaling [27, 28]. The remaining rarer mutations were observed in exons 9, 11, 13, and 17 (Fig. 1A).

Further downstream, the NRAS enzyme has a GTP/GDP binding and GTPase activity resulting in the activation of RAF proteins. Mutations may result in reduced intrinsic GTPase activity resulting in constitutive activation [29, 30]. NRAS mutations occur in $10.2 \%$ of VMs (Table 1), which is less common than in cutaneous and vaginal melanomas [23, $26,31]$. A meta-analysis has shown that NRAS mutations are more frequent in patients with nodular melanomas, which account only for a smaller portion of VMs and are more common in vaginal melanomas [2, 32]. Mutations most commonly affect the regions G12, G13 (exon 2), and Q61 (exon 3), both resulting in abnormal phosphorylation of downstream molecules (Fig. 1B) [31, 33].

$B R A F$ mutations have been reported in up to $70 \%$ of cutaneous melanomas and represent a therapeutic target for BRAF inhibitors alone or in combination with MEK inhibitors [26]. Combining previously published studies, $B R A F$ mutations are found in only $8.2 \%$ of VMs, most of which affect codon 600 (Fig. 1C). In contrast, BRAF mutations are common in typical and atypical nevi of the vulva [34, 35]. The same has been reported in the remaining skin, where up to $80 \%$ of benign nevi harbor activating $B R A F$ mutations [26]. Studies have suggested that $\mathrm{p} 16^{\text {INK4a }}$ expression in benign nevi induces senescence by preventing the progression from the G1 to the $\mathrm{S}$ phase. For a malignant transformation of nevi, additional alterations accompanying $B R A F$ mutations must therefore be present [26]. The high discrepancy between $B R A F$ mutations found in benign vulvar nevi and VMs, however, further supports the hypothesis that VMs develop independently from pre-existing nevi.

Cancer immunobiology is another important aspect that has fundamentally improved our understanding of cancerogenesis and provided us with new treatment modalities with ground-breaking success in melanoma. T cells recognize foreign antigens loaded on the major histocompatibility complex. At the same time, activating and inhibiting costimulatory signals regulate the T-cell immunity preventing
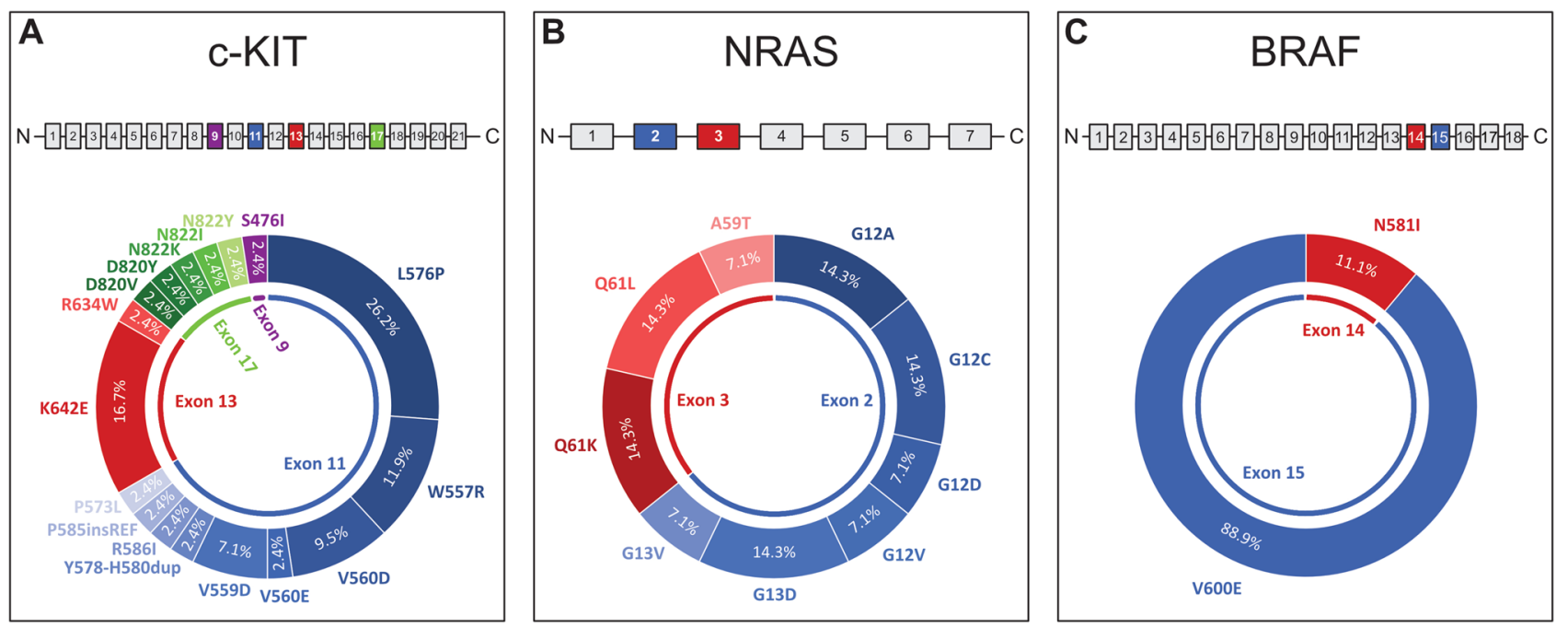

Fig. 1 A-C Summary of the frequencies of $c-K I T, N R A S$, and BRAF mutations from previously published studies that reported details on vulvar melanomas. The affected exons are highlighted in blue, red, and green and the corresponding mutations are shown in different gradations of blue, red, and green. A In $c$-KIT, $66.7 \%$ of the muta- tions were located on exon $11,19.0 \%$ on exon $13,11.9 \%$ on exon 17 , and $2.4 \%$ on exon $9 . \mathbf{B}$ In NRAS, $64.3 \%$ of the mutations were located on exon 2 and $35.7 \%$ on exon 3. C In $B R A F, 88.9 \%$ were located on exon 15 and $11.1 \%$ on exon 14 
autoimmunity under physiological conditions [36]. One of the key negative regulating mechanisms (immune checkpoints) is the B7:CD28 family, which includes CTLA-4, PD-1, and its ligands PD-L1 and PD-L2. During cancerogenesis, cancer cells must acquire mechanisms to escape immune surveillance and destruction, in which CTLA-4 and PD-1 with their ligands B7 and PD-L1 play a significant role in melanoma [36]. Studies have shown that PD-L1 is frequently expressed in VMs and checkpoint inhibitors represent a treatment option (see below) [37, 38].

\section{Prognosis}

Overall, women with VM have a poor prognosis. As shown in Fig. 2, the 5-year overall survival rate is only $46.6 \%$ compared with $92 \%$ in cutaneous melanoma [1]. Previous studies suggest that age, ethnicity, stage at diagnosis, tumor thickness, lymph node status, histologic subtype, mitotic count, ulceration, lymphovascular invasion, perineural invasion, and microscopic satellitosis are predictors for outcome [2, 10, 39-44]. In multivariable logistic regression analyses, lymph node status and mitotic count appear to be the most important predictors for survival $[2,39,40]$. The latter is especially important as mitotic count is not included in the

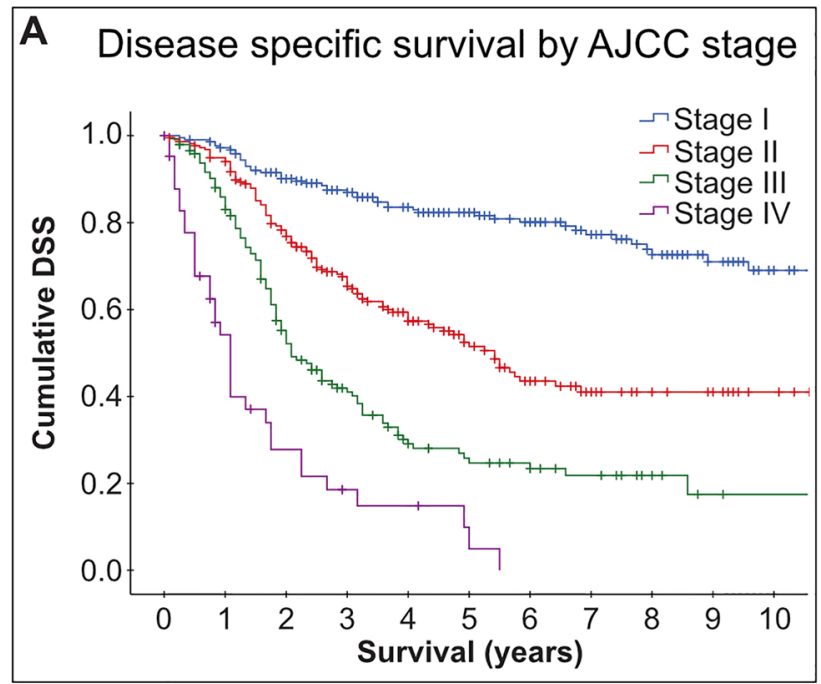

\begin{tabular}{|c|c|c|c|c|c|c|c|c|c|c|c|}
\hline & Years & 1 & 2 & 3 & 4 & 5 & 6 & 7 & 8 & 9 & 10 \\
\hline & Stage I & 97.2 & 90.1 & 86.9 & 83.5 & 82.3 & 80.1 & 77.2 & 72.6 & 71.0 & 69.0 \\
\hline & Sta & 94. & 76.8 & 65.4 & 57.3 & 51.5 & 43.5 & 41.0 & 41.0 & 41.0 & 41.0 \\
\hline & Stage III & 83.0 & 52.2 & 41.0 & 29.1 & 24.7 & 23.4 & 21.8 & 21.8 & 17.5 & 17.5 \\
\hline & Stage IV & 54.2 & 27.8 & 18.5 & 14.8 & 4.9 & 0 & 0 & 0 & 0 & 0 \\
\hline & All stages & 88.0 & 72.1 & 64.3 & 58.0 & 54.3 & 50.5 & 48.7 & 46.2 & 45.0 & 44.3 \\
\hline
\end{tabular}

Fig. 2 Disease-specific survival (DSS) [A] and overall survival (OS) $[\mathbf{B}]$ of primary malignant melanoma of the vulva by American Joint Committee on Cancer (AJCC) stages derived from the Surveillance, Epidemiology and End Results-18 population between 2000 and 2017 current staging system [45]. Nagarajan et al. have shown that women with a low mitotic count $\left(0-1\right.$ mitotic figures $\left./ \mathrm{mm}^{2}\right)$ have a significantly better outcome compared with women with a high $\left(2-10\right.$ mitotic figures $\left./ \mathrm{mm}^{2}\right)$ or very high $(>10$ mitotic figures $/ \mathrm{mm}^{2}$ ) mitotic count, which we confirmed in a subsequent study, where the number of mitotic figures was independently associated with disease-specific survival (hazard ratio $1.11,95 \%$ confidence interval [CI] 1.02-1.21) [39]. Lymph node metastasis was associated with a hazard ratio of 3.15 (95\% CI 1.54-6.45) [2]. In the era of immune checkpoint inhibitors, the importance of lymph node status as a prognostic factor may even be higher, as we are now able to offer adjuvant treatment in lymph node-positive VMs (see below).

\section{Diagnosis}

Clinically, VMs may remain oligosymptomatic or asymptomatic flat or raised pigmented lesions during early disease stages $[2,10]$. Amelanotic melanomas account for only $2 \%$ of all VMs [2]. At the time of diagnosis, the lesions present with a mean size of $3 \mathrm{~cm}$ (standard deviation \pm $4 \mathrm{~cm}$ ) and may be associated with pruritus, ulceration, or

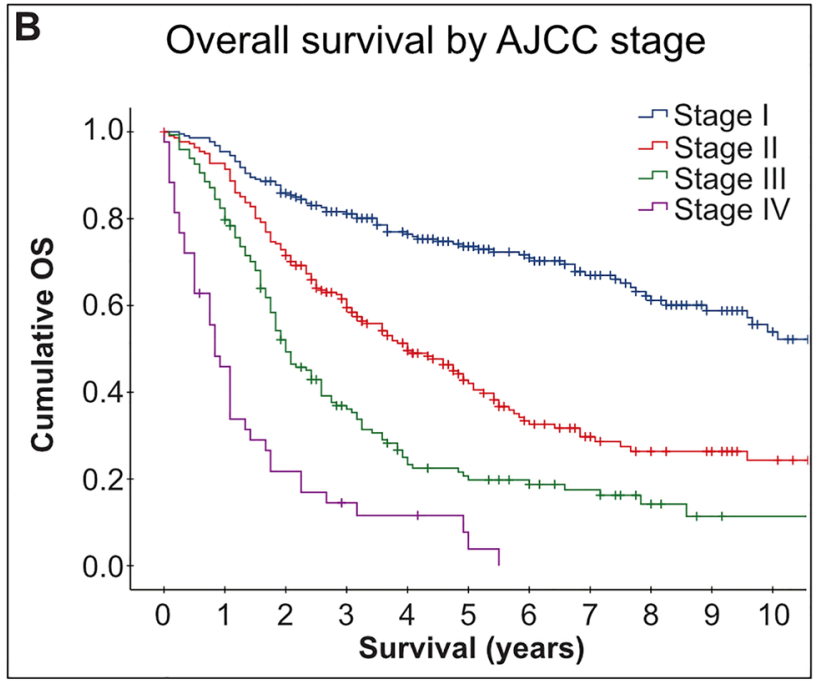

\begin{tabular}{|c|c|c|c|c|c|c|c|c|c|c|c|}
\hline \multirow{5}{*}{ 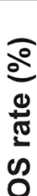 } & Years & 1 & 2 & 3 & 4 & 5 & 6 & 7 & 8 & 9 & 10 \\
\hline & Stage I & 95.5 & 85.9 & 81.1 & 76.4 & 73.6 & 70.9 & 67.0 & 61.2 & 58.8 & 53.9 \\
\hline & ge & 1.4 & 71.5 & 59.5 & 9.6 & 42.0 & 32.6 & 29.7 & 26.3 & 26.3 & 24.3 \\
\hline & Stage III & 79.7 & 49.3 & 36.1 & 23.3 & 19.8 & 18.7 & 17.5 & 14.2 & 11.4 & 11.4 \\
\hline & Sta & 45.9 & 21.7 & 14.5 & 11.6 & 3.8 & 0 & 0 & 0 & 0 & 0 \\
\hline & All stages & 84.8 & 67.2 & 58.5 & 51.1 & 46.6 & 42.4 & 39.3 & 35.1 & 33.8 & 32.1 \\
\hline
\end{tabular}

(November 2019 submission) of the National Cancer Institute [135]. In the lower part of the figure, the DSS and OS rates by year are shown for AJCC stages I-IV and all stages combined 
bleeding-symptoms that typically occur in advanced stages of melanoma [2, 46].

Differential diagnoses of pigmented vulvar lesions include genital nevi, vulvar melanosis, post-inflammatory hyperpigmentation, low-grade and high-grade squamous intraepithelial lesions, differentiated vulvar intraepithelial neoplasia, and pigmented seborrheic keratosis [47-49]. Differentiation of VMs from benign vulvar lesions is often challenging and sometimes impossible to make based on the clinical judgment alone. The "ABCDE" rule may aid as a simple guide for a first assessment of pigmented lesions: "A" stands for asymmetry and most melanomas are asymmetrical; "B" stands for border as melanomas typically exhibit an irregular border, while nevi typically have a smoother border. "C" stands for color. While benign moles are often unicolor brown, multiple colors including different shades of brown, black, blue, white, or red are typically a sign for malignancy. " $D$ " stands for diameter and lesions greater than $6 \mathrm{~mm}$ should raise awareness. "E" stands for elevation or evolving and any change of shape, size, structure, color, or symptoms is a potential indicator for malignancy [50].

The introduction of dermoscopy as a diagnostic tool and the development of several algorithms have improved the early detection of cutaneous malignant melanoma over recent years [51]. In contrast to cutaneous melanoma, studies on the dermoscopy of VMs are limited by small case numbers. Table 2 summarizes the dermoscopy features of VMs from a total of 38 patients identified in the literature. The most common features were asymmetry of structure and color (91.7\%), blue-white veil or blue-gray areas (68.4\%), structureless areas $(47.4 \%)$, irregular dots and globules (42.1\%), atypical vessels (42.1\%), irregular network or atypical patterns $(34.2 \%)$, and reticular depigmentation (16.7\%). The characteristic dermoscopy features in VM are shown in Fig. 3. A retrospective study by the International Dermoscopy Society evaluated the application of dermoscopy for genital lesions and suggested that the presence of a blue, gray, or white color plus the presence of a structureless zone had a sensitivity of $100 \%$ and a specificity of $82.2 \%$ to detect a melanoma [52]. Ferrari et al. proposed that a multicomponent pattern composed of irregular brown-black dots, blue-white veil, atypical vessels, and reticular depigmentation appear to be characteristic features for VMs [53]. However, there remains a significant overlap between benign and malignant lesions and a biopsy should be performed in all suspicious lesions for a definitive diagnosis. Particularly with larger or multiple lesions, meticulous mapping of the biopsy site is mandatory and the position on the clock face with distance from the midline and vaginal introitus as well as the anatomic location should be reported [46].

If $\mathrm{VM}$ is confirmed on biopsy, staging should be based on the American Joint Committee on Cancer (AJCC) staging system instead of the FIGO staging system used for vulvar squamous cell carcinoma, as the AJCC has been found to be a better predictor of survival in the prospective GOG-73 study and this was recently confirmed by a large populationbased study [2, 42]. The AJCC staging system is currently in its eighth edition and the staging of the primary tumor ( $\mathrm{T}$ category) is based on Breslow's thickness and the presence/ absence of ulceration [45]. Histologic grading is not used in melanomas, but the lesion is classified into one of the histopathologic subtypes: superficial spreading, nodular, lentigo maligna, acral lentiginous, and desmoplastic [45]. Women with superficial spreading VM appear to have a better prognosis compared with those with nodular melanomas [2].

Because of the often advanced disease stages, pre-operative imaging is recommended [46, 54]. Magnetic resonance imaging may be useful to delineate the disease extent and for surgical planning. Computed tomography or positron emission tomography-computed tomography may be used for the evaluation of regional and/or distant metastases [46].

\section{Surgical Treatment}

The primary treatment modality for localized melanoma is surgical excision. In cutaneous melanoma, the National Comprehensive Cancer Network and European Society for Medical Oncology guidelines recommend surgical margins depending on tumor thickness (based on category I evidence): $0.5-1 \mathrm{~cm}$ for melanoma in situ, $1 \mathrm{~cm}$ for invasive melanoma with a Breslow's thickness $\leq 1 \mathrm{~mm}, 1-2 \mathrm{~cm}$ for Breslow 1.01-2 mm, and $2 \mathrm{~cm}$ for Breslow $>2 \mathrm{~mm}$. Noteworthy, these are based on measured clinical margins taken at the time of surgery and not gross or histologic margins, as measured by the pathologist $[55,56]$. The same margins must apply for VM. However, in accordance with the National Comprehensive Cancer Network guidelines, margins may be modified to accommodate individual anatomic or functional considerations, which may be considered in VM in terms of preservation of continence and sexual function $[46,55]$. Although urinary incontinence has been reported after surgical resection of vulvar cancer, a partial resection of $1-1.5 \mathrm{~cm}$ of the distal urethra, if required for a complete excision, does not appear to be associated with an increased risk for urinary incontinence $[57,58]$. The GOG73 trial, the only prospective study on VM performed to date, and retrospective data indicate that more radical vulva surgeries such as primary vulvectomy are not associated with a better oncologic outcome compared with a local excision using the margins above, but are associated with an increased complication rate $[10,15,42,59,60]$.

Sentinel lymph node biopsy should be offered to all women with VM and clinically unsuspicious nodes if the AJCC stage is greater than IA or in the presence of ulceration [55-56]. The Multicentre Selective Lympadenectomy 


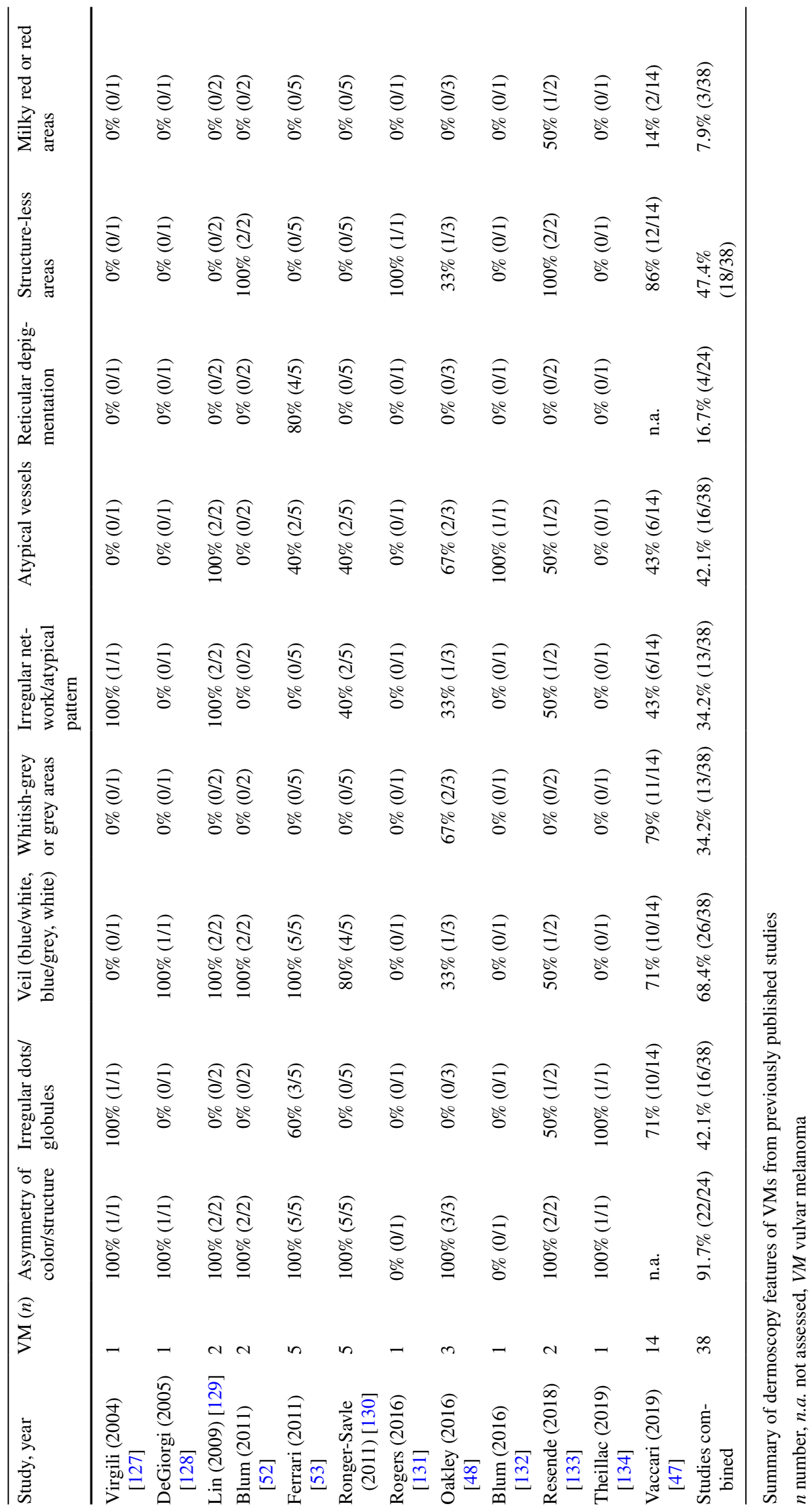


Fig. 3 Characteristic dermoscopy features of malignant melanomas of the vulva

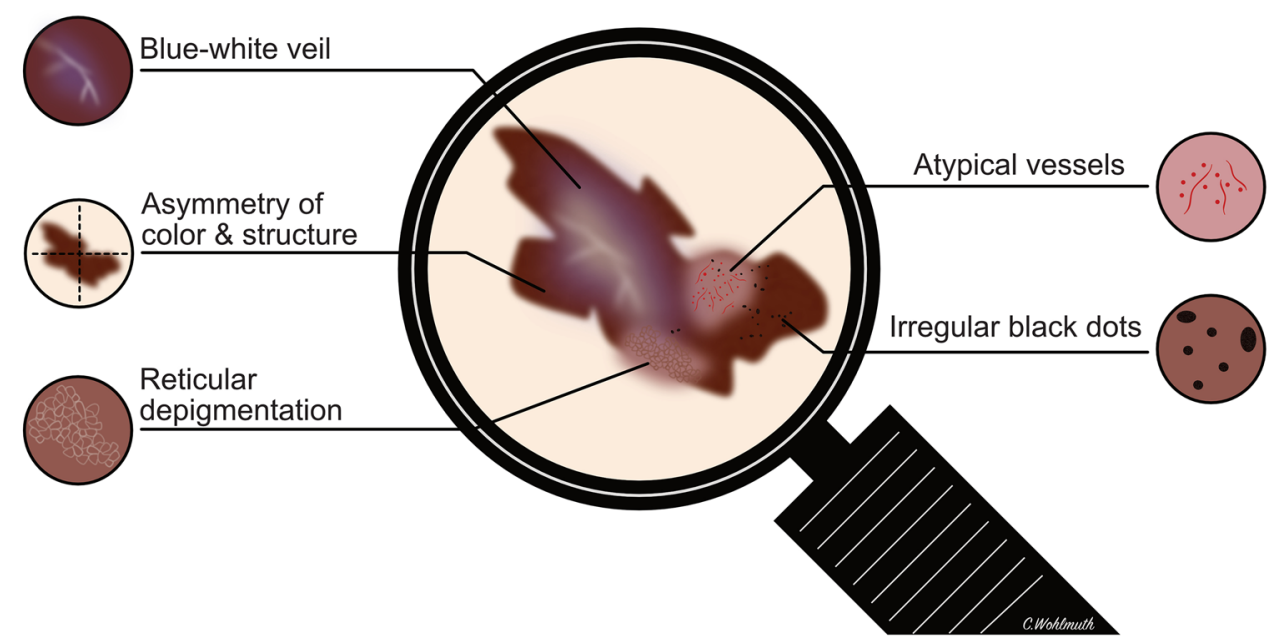

Trial I has validated the staging potential of sentinel lymph node biopsy but did not show an unequivocal survival benefit in terms of treatment-related 10-year melanoma-specific survival [61]. Noteworthy, the study enrolled patients between 1994 and 2002, in the era before adjuvant treatment with checkpoint inhibitors was offered to node-positive patients. Sentinel lymph node biopsy has been extensively studied in vulvar cancer. A meta-analysis has shown that the detection rate using blue dye in combination with radiocolloid tracer is $97.7 \%$ (95\% CI 96.6-98.5) if ultra-staging and immunohistochemistry is performed [62]. A similar detection rate of $98.3 \%$ has been reported in a literature review of VMs [63].

More recently, near-infrared fluorescence imaging with indocyanine green has been implemented to visualize sentinel lymph nodes in gynecologic cancers. Prospective and retrospective studies suggest that indocyanine green is as good as radiocolloids and blue dye or may even improve the detection rate of the sentinel lymph node [64, 65]. In lateral vulvar tumors, a unilateral sentinel lymph node biopsy is usually sufficient; however, in primary tumors that are within $2 \mathrm{~cm}$ of, or crossing, the vulvar midline, a bilateral evaluation is warranted $[66,67]$. Lymphoscintigraphy with radiocolloid tracers aids in the identification of unilateral vs bilateral sentinel nodes [68].

For patients with a positive sentinel node, two randomized-controlled phase III studies have shown no difference in melanoma-specific or overall survival in patients undergoing completion lymphonodectomy compared to those who underwent nodal basin ultrasound surveillance [55, 69, 70]. The Multicentre Selective Lympadenectomy Trial II trial indicated a lower rate of regional recurrence, which did not translate into a survival benefit and was associated with an almost four times higher rate of lymphedema [69]. Although these studies investigated patients with cutaneous melanomas, this likely translates into VM, where the complication rates of full inguinofemoral lymph node dissection are high [68, 71]. In women with clinically apparent lymph node metastases, therapeutic lymph node dissection combined with local excision is indicated after excluding distant metastases [55, 56, 72]. A summary of the key surgical steps and relevant anatomical landmarks is shown in Fig. 4.

\section{Medical Treatment}

Before the era of immune checkpoint inhibitors and targeted therapy, women with unresectable or metastatic VM were typically offered cytotoxic chemotherapy, which was associated with response rates between 12 and $26 \%$ without improving survival [73-75]. Polychemotherapy regimens are not associated with better survival compared to singleagent chemotherapy and interferon-alpha and interleukin-2 improve progression-free survival, but not overall survival [76]. With the US Food and Drug Administration and European Medicines Agency approval of CTLA-4, PD-1, BRAF, and MEK Inhibitors, the medical treatment of melanoma has drastically changed accompanied by ground-breaking improvements of survival [46, 77-80].

Many of the landmark trials allowed the inclusion of mucosal melanomas and VMs. A pooled post-hoc analysis of six clinical trials [81-86] on the efficacy and safety of ipilimumab and nivolumab suggested a lower response rate in mucosal melanomas compared with cutaneous melanomas. The objective response rate (ORR) for ipilimumab monotherapy was $8.3 \%$ (95\% CI 1.8-22.5\%), for nivolumab alone $23.3 \%$ (95\% CI 14.8-33.6), and for a combination therapy with ipilimumab and nivolumab $37.1 \%$ (95\% CI 21.5-55.1) [87]. However, the analysis included all mucosal melanomas without separately reporting the disease sites. Similarly, a post hoc analysis on the efficacy and safety of pembrolizumab in 84 patients with mucosal melanoma 

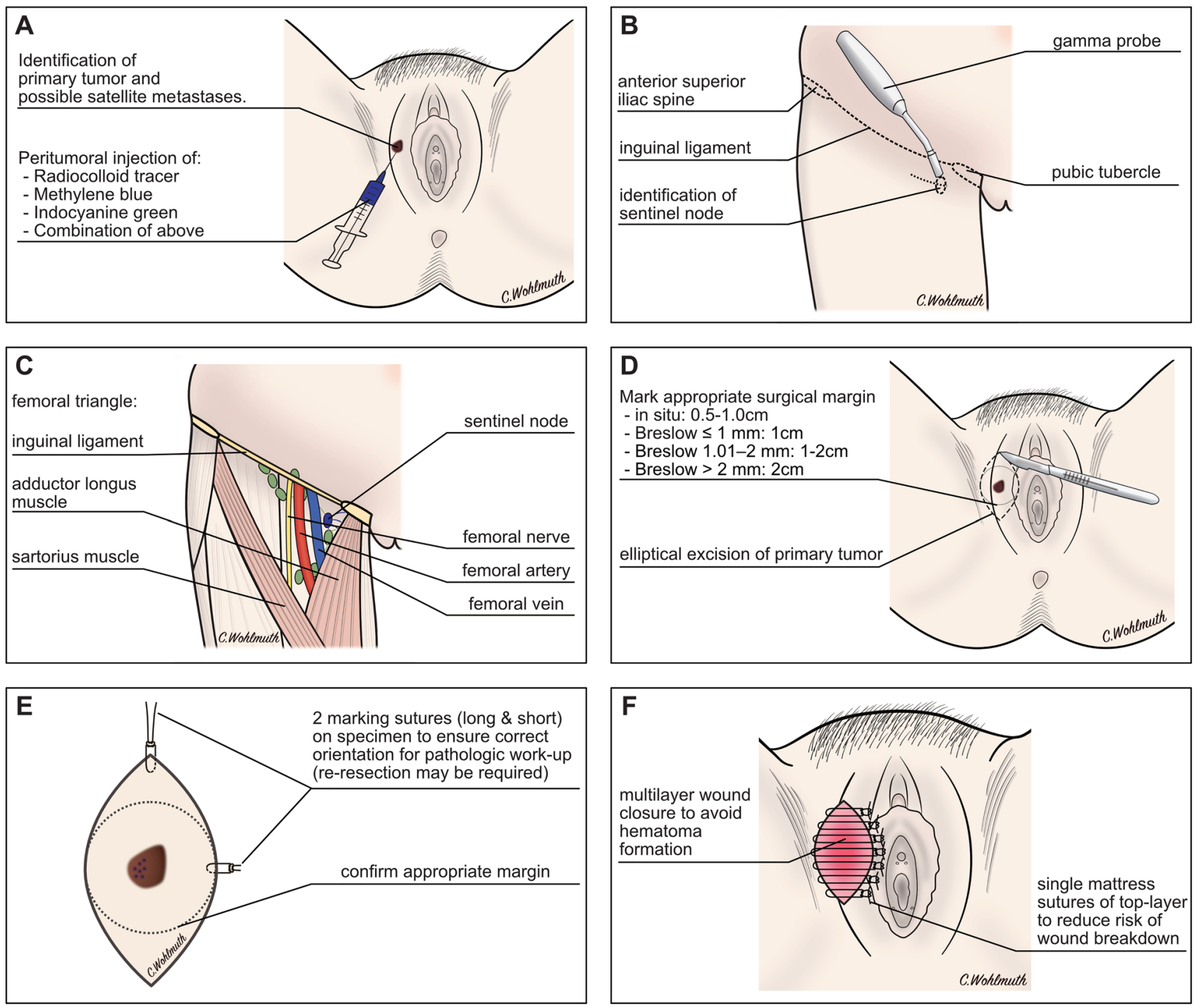

Fig. 4 A-F Key steps in the surgical management of vulvar melanoma. The sentinel technique is now considered standard of care in the management of vulvar cancer and melanoma in women with clinically negative lymph nodes. Radiocolloid tracers, methylene blue dye, indocyanine green, or a combination of these can be used to locate the sentinel node in vulvar melanoma (A). Radiocolloid tracers facilitate the localization of the sentinel node using a gamma probe and a small incision is made at the region of the located sentinel node (B). The anatomical landmarks of the femoral triangle are the inguinal ligament, the adductor longus muscle, and the sartorius muscle. The sentinel node can be visualized if methylene blue or indocyanine

pooled from the KEYNOTE-001, 002, and 006 trials [79, $88,89]$ was performed: the ORR for pembrolizumab was $19 \%$ (95\% CI 11-29) with anti-tumor activity observed in ipilimumab-naive and ipilimumab pre-treated patients [90]. Again, the disease site was not specified.

We have recently published our data on CTLA-4 and PD-1 inhibitor treatment in vulvovaginal melanomas at the Princess Margaret Cancer Centre in Toronto [11]. Women

green have been used and confirmed with a gamma probe if radiocolloid tracers have been injected (C). If possible, a local wide excision is usually preferred over more radical procedures. The suggested surgical margin depends on the depth of invasion, i.e. Breslow's thickness of the primary tumor (D). The specimen should be marked for further pathologic work-up in the anatomically correct orientation in case a re-resection due to R1 status is necessary $(\mathbf{E})$. The wound should be closed in layers to reduce the risk of hematoma formation. The top layer is often closed using single mattress sutures to reduce the risk of wound breakdown $(\mathbf{F})$.

with VM treated with ipilimumab had an ORR of $12.5 \%$ (95\% CI 0-35.4) and the disease control rate (DCR) was $25.0 \%$ (95\% CI 0-55.0). For PD-1 inhibitors or a combination of CTLA- 4 and PD-1 inhibitors, the ORR was $33.3 \%$ (95\% CI 2.5-64.1) and the DCR was 66.7\% (95\% CI 35.9-97.5). In addition, previously published case reports and case series on immune checkpoint inhibitors in VMs were analyzed separately and showed similar ORRs [11]. 
The safety profile and rate of grade 3 or 4 immune-related adverse events were comparable to cutaneous melanomas with a range of $8-13 \%$ for monotherapy and up to $40 \%$ with combination treatment $[11,87,90]$. Therefore, immune checkpoint inhibitors should be offered to all women with unresectable or metastatic VMs, although the response rates may be slightly lower compared with cutaneous melanomas. Other immune checkpoints that are currently under investigation include LAG3, TIM3, and OX40 [91-93].

As shown in Table 1, c-KIT mutations are present in $>20 \%$ of VMs. Tyrosine kinase inhibitors may therefore be considered in recurrent VM. While studies have shown that tyrosine kinase inhibitors are ineffective in unselected cases of advanced melanoma, it may be considered in those patients harboring a $c-K I T$ mutation [94-96]. In three phaseII clinical trials, a total of 92 patients with melanoma with $c$-KIT mutations were given imatinib. The ORR range was 16-29\% and the DCR was 36-54\% [97-99]. Nilotinib, a different tyrosine kinase inhibitor that was originally approved for imatinib-resistant chronic myeloid leukemia, was also tested in a total of $135 c$-KIT-mutated melanomas in five phase II trials. The reported ORR range was $16-26 \%$ and the DCR was $53-78 \%$. Nilotinib was generally well tolerated with grade $3 / 4$ toxicities observed in approximately $20 \%$, the most common being elevated hepatic and pancreatic enzymes [100-104].

Although the sample size of the studies was limited, the authors observed that most of the responders harbored $c$-KIT mutations located on exons 11 and 13 [102, 104]. In our literature review, $85.7 \%$ of $c-K I T$ mutations found in VMs were located in these exons (Fig. 1A). Other tyrosine kinase inhibitors that have been used include sunitinib [105, 106], dasatinib [107, 108], and sorafenib [109].

With $B R A F$ mutations being relatively rare, targeted treatment with a combination of BRAF and MEK inhibitors plays a less important role in VMs (Table 1). The recently published American Society of Clinical Oncology guidelines on systemic therapy, however, suggest that a combination therapy with the BRAF/MEK inhibitors dabrafenib/trametinib, encorafenib/binimetinib, or vemurafenib/cobimetinib may also be offered in $B R A F$-mutant mucosal melanomas [110].

Data regarding adjuvant treatment in mucosal melanomas remain scarce. Most clinical trials on adjuvant therapy in melanoma (including the EORTC-18071 and Keynote-054 protocol) have either excluded mucosal melanoma or did not further specify melanoma subtypes [46, 111-113]. The CheckMate-238 trial included 29 patients with mucosal melanomas, of whom 16 received nivolumab, but the study was not sufficiently powered to show differences in the subgroups [114].

The American Society of Clinical Oncology guidelines suggest that patients with mucosal melanomas should be offered the same therapies recommended for cutaneous melanomas. Nivolumab or pembrolizumab should thus be offered to patients with resected stage IIIA/B/C/D BRAF wild-type VMs, while either of those two agents or the combination of dabrafenib and trametinib may be considered in $B R A F$-mutant disease [110]. Several clinical trials (NCT03241186, NCT04462965, NCT03178123, NCT04180995, NCT04622566) are currently ongoing that may further guide adjuvant and neoadjuvant treatment of mucosal melanomas in the near future (www.clinicaltrials. gov).

\section{Conclusions}

Vulvar melanomas represent an important subclass of melanomas with distinct molecular characteristics. Diagnosis is often delayed with $38 \%$ being diagnosed at advanced disease stages and the prognosis of women with VMs remains dismal. With often overlapping features between benign and malignant lesions, the threshold to biopsy suspicious lesions should be kept low. Surgery remains the primary treatment modality for localized melanoma and should include a sentinel node biopsy. Adjuvant treatment with nivolumab or pembrolizumab should be discussed with nodal involvement. Medical treatment with checkpoint inhibitors should be offered to women with unresectable or metastatic VMs and tyrosine kinase inhibitors may be considered in recurrent disease if a $c$-KIT mutation is identified.

Author Contributions CW: conceptualization, literature review, methodology, analysis, figures, writing of the manuscript. IWW: literature review, methodology, analysis, review and editing of the manuscript. All authors read and approved the final manuscript.

Funding Open access funding provided by Paracelsus Medical University.

\section{Declarations}

Funding Iris Wohlmuth-Wieser received a grant from the Austrian Science Fund (FWF), project number J-4382.

Conflicts of interest/Competing interests Christoph Wohlmuth and Iris Wohlmuth-Wieser have no conflicts of interest that are directly relevant to the content of this article.

Ethics approval No ethics approval was required for the preparation of this review article.

Consent to participate Not applicable.

Consent for publication Not applicable. 
Availability of data and material All data are available in this published article and are available from the corresponding author on reasonable request.

Code availability Not applicable.

Open Access This article is licensed under a Creative Commons Attribution-NonCommercial 4.0 International License, which permits any non-commercial use, sharing, adaptation, distribution and reproduction in any medium or format, as long as you give appropriate credit to the original author(s) and the source, provide a link to the Creative Commons licence, and indicate if changes were made. The images or other third party material in this article are included in the article's Creative Commons licence, unless indicated otherwise in a credit line to the material. If material is not included in the article's Creative Commons licence and your intended use is not permitted by statutory regulation or exceeds the permitted use, you will need to obtain permission directly from the copyright holder. To view a copy of this licence, visit http://creativecommons.org/licenses/by-nc/4.0/.

\section{References}

1. Siegel RL, Miller KD, Jemal A. Cancer statistics, 2020. CA Cancer J Clin. 2020;70:7-30.

2. Wohlmuth C, Wohlmuth-Wieser I, May T, Vicus D, Gien LT, Laframboise S. Malignant melanoma of the vulva and vagina: a US population-based study of 1863 patients. Am J Clin Dermatol. 2020;21:285-95.

3. Ragnarsson-Olding B, Johansson H, Rutqvist LE, Ringborg U. Malignant melanoma of the vulva and vagina: trends in incidence, age distribution, and long-term survival among 245 consecutive cases in Sweden 1960-1984. Cancer. 1993;71:1893-7.

4. Hassanein AM, Mrstik ME, Hardt NS, Morgan LA, Wilkinson EJ. Malignant melanoma associated with lichen sclerosus in the vulva of a 10-year-old. Pediatr Dermatol. 2004;21:473-6.

5. Egan CA. Vulvar melanoma in childhood. Arch Dermatol. 1997;133:345-8.

6. La Spina M, Meli MC, De Pasquale R, Perrotta RE, Lanzafame $\mathrm{S}$, Caltabiano R, et al. Vulvar melanoma associated with lichen sclerosus in a child: case report and literature review. Pediatr Dermatol. 2016;33:e190-4.

7. Rosamilia LL, Schwartz JL, Lowe L, Gruber SB, Quint EH, Johnson TM, et al. Vulvar melanoma in a 10-year-old girl in association with lichen sclerosus. J Am Acad Dermatol. 2006;54:S52-3.

8. Friedrich EG, Burch K, Bahr JP. The vulvar clinic: an eightyear appraisal. Am J Obstet Gynecol. 1979;135:1036-40.

9. Rock B, Hood AF, Rock JA. Prospective study of vulvar nevi. J Am Acad Dermatol. 1990;22:104-6.

10. Verschraegen CF, Benjapibal M, Supakarapongkul W, Levy LB, Ross M, Atkinson EN, et al. Vulvar melanoma at the M. D. Anderson Cancer Center: 25 years later. Int J Gynecol Cancer. 2001;11:359-64

11. Wohlmuth C, Wohlmuth-Wieser I, Laframboise S. Clinical characteristics and treatment response with checkpoint inhibitors in malignant melanoma of the vulva and vagina. J Low Genit Tract Dis. 2021;25:146-51.

12. Scheistrøen M, Tropé C, Koern J, Pettersen EO, Abeler VM, Kristensen GB. Malignant melanoma of the vulva: evaluation of prognostic factors with emphasis on DNA ploidy in 75 patients. Cancer. 1995;75:72-80.
13. Wechter ME, Gruber SB, Haefner HK, Lowe L, Schwartz JL, Reynolds KR, et al. Vulvar melanoma: a report of 20 cases and review of the literature. J Am Acad Dermatol. 2004;50:554-62.

14. Ragnarsson-Olding BK, Kanter-Lewensohn LR, Lagerlöf B, Nilsson BR, Ringborg UK. Malignant melanoma of the vulva in a nationwide, 25-year study of 219 Swedish females: clinical observations and histopathologic features. Cancer. 1999;86:1273-84.

15. Räber G, Mempel V, Jackisch C, Hundeiker M, Heinecke A, Kürzl R, et al. Malignant melanoma of the vulva: report of 89 patients. Cancer. 1996;78:2353-8.

16. Pleunis N, Schuurman MS, Van Rossum MM, Bulten J, Massuger LF, De Hullu JA, et al. Rare vulvar malignancies; incidence, treatment and survival in the Netherlands. Gynecol Oncol. 2016;142:440-5.

17. Hieta N, Kurki S, Rintala M, Söderlund J, Hietanen S, Orte K. Association of vulvar melanoma with lichen sclerosus. Acta Derm Venereol. 2019;99:339-40.

18. Heinzelmann-Schwarz VA, Nixdorf S, Valadan M, Diczbalis M, Olivier J, Otton G, et al. A clinicopathological review of 33 patients with vulvar melanoma identifies c-KIT as a prognostic marker. Int J Mol Med. 2014;33:784-94.

19. Besmer P, Murphy JE, George PC, Qiu F, Bergold PJ, Lederman $\mathrm{L}$, et al. A new acute transforming feline retrovirus and relationship of its oncogene v-kit with the protein kinase gene family. Nature. 1986;320:415-21.

20. Yarden Y, Kuang WJ, Yang-Feng T, Coussens L, Munemitsu S, Dull TJ, et al. Human proto-oncogene c-kit: a new cell surface receptor tyrosine kinase for an unidentified ligand. EMBO J. 1987;6:3341-51.

21. Curtin JA, Busam K, Pinkel D, Bastian BC. Somatic activation of KIT in distinct subtypes of melanoma. J Clin Oncol. 2006;24:4340-6.

22. Willmore-Payne C, Holden JA, Tripp S, Layfield LJ. Human malignant melanoma: detection of BRAF- and c-kit-activating mutations by high-resolution amplicon melting analysis. Hum Pathol. 2005;36:486-93.

23. Hou JY, Baptiste C, Hombalegowda RB, Tergas AI, Feldman $\mathrm{R}$, Jones NL, et al. Vulvar and vaginal melanoma: a unique subclass of mucosal melanoma based on a comprehensive molecular analysis of 51 cases compared with 2253 cases of nongynecologic melanoma. Cancer. 2017;123:1333-44.

24. Omholt K, Grafström E, Kanter-Lewensohn L, Hansson J, Ragnarsson-Olding BK. KIT pathway alterations in mucosal melanomas of the vulva and other sites. Clin Cancer Res. 2011;17:3933-42.

25. Zarei S, Voss JS, Jin L, Jenkins SM, Bryce AH, Erickson LA, et al. Mutational profile in vulvar, vaginal, and urethral melanomas: review of 37 cases with focus on primary tumor site. Int J Gynecol Pathol. 2020;39:587-94.

26. Gray-Schopfer V, Wellbrock C, Marais R. Melanoma biology and new targeted therapy. Nature. 2007;445:851-7.

27. Vanderwinden JM, Wang D, Paternotte N, Mignon S, Isozaki $\mathrm{K}$, Erneux C. Differences in signaling pathways and expression level of the phosphoinositide phosphatase SHIP1 between two oncogenic mutants of the receptor tyrosine kinase KIT. Cell Signal. 2006; 18:661-9.

28. Monsel G, Ortonne N, Bagot M, Bensussan A, Dumaz N. c-Kit mutants require hypoxia-inducible factor 1alpha to transform melanocytes. Oncogene. 2010;29:227-36.

29. Bos JL. Ras oncogenes in human cancer: a review. Cancer Res. 1989;49:4682-9.

30. Rouzbahman M, Kamel-Reid S, Al Habeeb A, Butler M, Dodge $\mathrm{J}$, Laframboise $\mathrm{S}$, et al. Malignant melanoma of vulva and vagina. J Low Genit Tract Dis. 2015;19:350-3. 
31. Grill C, Larue L. NRAS, NRAS, which mutation is fairest of them all? J Invest Dermatol. 2016;136:1936-8.

32. Lee J-H, Choi J-W, Kim Y-S. Frequencies of BRAF and NRAS mutations are different in histological types and sites of origin of cutaneous melanoma: a meta-analysis. Br J Dermatol. 2011;164:776-84.

33. Posch C, Sanlorenzo M, Vujic I, Oses-Prieto JA, Cholewa BD, Kim ST, et al. Phosphoproteomic analyses of NRAS $(\mathrm{G} 12)$ and NRAS(Q61) mutant melanocytes reveal increased CK2 $\alpha$ kinase levels in NRAS(Q61) mutant cells. J Invest Dermatol. 2016;136:2041-8.

34. Tseng D, Kim J, Warrick A, Nelson D, Pukay M, Beadling C, et al. Oncogenic mutations in melanomas and benign melanocytic nevi of the female genital tract. J Am Acad Dermatol. 2014;71:229-36.

35. Nguyen LP, Emley A, Wajapeyee N, Green MR, Mahalingam $\mathrm{M}$. BRAF V600E mutation and the tumour suppressor IGFBP7 in atypical genital naevi. Br J Dermatol. 2010;162:677-80.

36. Tsai KK, Zarzoso I, Daud AI. PD-1 and PD-L1 antibodies for melanoma. Hum Vaccin Immunother. 2014;10:3111-6.

37. Saleh B, Kriegsmann J, Falk S, Aulmann S. Frequent PD-L1 expression in malignant melanomas of the vulva. Int J Gynecol Pathol. 2018;37:477-81.

38. Furlan K, Rohra P, Mir F, Gattuso P. Non-human papillomavirus related malignancies of the vulva: a clinicopathological study. J Cutan Pathol. 2020;47:917-22.

39. Nagarajan P, Curry JL, Ning J, Piao J, Torres-Cabala CA, Aung $\mathrm{PP}$, et al. Tumor thickness and mitotic rate robustly predict melanoma-specific survival in patients with primary vulvar melanoma: a retrospective review of 100 cases. Clin Cancer Res. 2017;23:2093-104.

40. Ditto A, Bogani G, Martinelli F, Di Donato V, Laufer J, Scasso $\mathrm{S}$, et al. Surgical management and prognostic factors of vulvovaginal melanoma. J Low Genit Tract Dis. 2016;20:e24-9.

41. Seifried S, Haydu LE, Quinn MJ, Scolyer RA, Stretch JR, Thompson JF. Melanoma of the vulva and vagina: principles of staging and their relevance to management based on a clinicopathologic analysis of 85 cases. Ann Surg Oncol. 2015;22:1959-66.

42. Phillips GL, Bundy BN, Okagaki T, Kucera PR, Stehman FB. Malignant melanoma of the vulva treated by radical hemivulvectomy: a prospective study of the Gynecologic Oncology Group. Cancer. 1994;73:2626-32.

43. Harting MS, Kim KB. Biochemotherapy in patients with advanced vulvovaginal mucosal melanoma. Melanoma Res. 2004;14:517-20.

44. Janco JMT, Markovic SN, Weaver AL, Cliby WA. Vulvar and vaginal melanoma: case series and review of current management options including neoadjuvant chemotherapy. Gynecol Oncol. 2013;129:533-7.

45. Gershenwald J, Scolyer R, Gardner J, Hess K, Thompson J, Long $\mathrm{G}$, et al. Melanoma of the skin. In: Amin MB et al., editors. AJCC cancer staging manual. 8th ed. New York: Springer; 2017. p. $563-88$.

46. Wohlmuth C, Wohlmuth-Wieser I. Vulvar malignancies: an interdisciplinary perspective. JDDG J der Dtsch Dermatologischen Gesellschaft. 2019;17:1257-76.

47. Vaccari S, Barisani A, Salvini C, Pirola S, Preti EP, Pennacchioli $\mathrm{E}$, et al. Thin vulvar melanoma: a challenging diagnosis: dermoscopic features of a case series. Clin Exp Dermatol. 2020;45:187-93.

48. Oakley A. Dermatoscopic features of vulval lesions in 97 women. Australas J Dermatol. 2016;57:48-53.

49. Venkatesan A. Pigmented lesions of the vulva. Dermatol Clin. 2010;28:795-805.
50. Liu W, Hill D, Gibbs AF, Tempany M, Howe C, Borland R, et al. What features do patients notice that help to distinguish between benign pigmented lesions and melanomas? The $\mathrm{ABCD}(\mathrm{E})$ rule versus the seven-point checklist. Melanoma Res. 2005;15:549-54.

51. Kittler H, Pehamberger H, Wolff K, Binder M. Diagnostic accuracy of dermoscopy. Lancet Oncol. 2002;3:159-65.

52. Blum A. Dermoscopy of pigmented lesions of the mucosa and the mucocutaneous junction: results of a multicenter study by the International Dermoscopy Society (IDS). Arch Dermatol. 2011;147:1181-7.

53. Ferrari A, Zalaudek I, Argenziano G, Buccini P, De Simone P, Silipo V, et al. Dermoscopy of pigmented lesions of the vulva: a retrospective morphological study. Dermatology. 2011;222:157-66.

54. Leitao MM, Cheng X, Hamilton AL, Siddiqui NA, JurgenliemkSchulz I, Mahner S, et al. Gynecologic Cancer InterGroup (GCIG) consensus review for vulvovaginal melanomas. Int J Gynecol Cancer. 2014;24:S117-22.

55. NCCN. NCCN clinical practice guidelines in oncology: cutaneous melanoma. Version 4. 2020. https://www.nccn.org. Accessed 7 Dec 2020.

56. Michielin O, van Akkooi ACJ, Ascierto PA, Dummer R, Keilholz U. Cutaneous melanoma: ESMO clinical practice guidelines for diagnosis, treatment and follow-up. Ann Oncol. 2019;30:1884-901.

57. de Mooij Y, Burger MPM, Schilthuis MS, Buist M, van der Velden J. Partial urethral resection in the surgical treatment of vulvar cancer does not have a significant impact on urinary continence: a confirmation of an authority-based opinion. Int J Gynecol Cancer. 2017;17:294-7.

58. Reid GC, DeLancey JO, Hopkins MP, Roberts JA, Morley GW. Urinary incontinence following radical vulvectomy. Obstet Gynecol. 1990;75:852-8.

59. Trimble EL, Lewis JL, Williams LL, Curtin JP, Chapman D, Woodruff JM, et al. Management of vulvar melanoma. Gynecol Oncol. 1992;45:254-8.

60. Gadducci A, Carinelli S, Guerrieri ME, Aletti GD. Melanoma of the lower genital tract: prognostic factors and treatment modalities. Gynecol Oncol. 2018;150:180-9.

61. Morton DL, Thompson JF, Cochran AJ, Mozzillo N, Nieweg OE, Roses DF, et al. Final trial report of sentinel-node biopsy versus nodal observation in melanoma. N Engl J Med. 2014;370:599-609.

62. Meads C, Sutton AJ, Rosenthal AN, Małysiak S, Kowalska M, Zapalska A, et al. Sentinel lymph node biopsy in vulval cancer: systematic review and meta-analysis. Br J Cancer. 2014;110:2837-46.

63. Lopez S, Guerrisi R, Brusadelli C, Bogani G, Ditto A, Raspagliesi $\mathrm{F}$. The role of sentinel lymph node mapping in lower genital tract melanoma. Minerva Ginecol. 2020;72:384-90.

64. Deken MM, van Doorn HC, Verver D, Boogerd LSF, de Valk KS, Rietbergen DDD, et al. Near-infrared fluorescence imaging compared to standard sentinel lymph node detection with blue dye in patients with vulvar cancer: a randomized controlled trial. Gynecol Oncol. 2020;159:672-80.

65. Broach V, Abu-Rustum NR, Sonoda Y, Brown CL, Jewell E, Gardner G, et al. Evolution and outcomes of sentinel lymph node mapping in vulvar cancer. Int J Gynecol Cancer. 2020;30:383-6.

66. NCCN. NCCN clinical practice guidelines in oncology: vulvar cancer. Version 2.2021. https://www.nccn.org. Accessed 9 Dec 2020.

67. Coleman RL, Ali S, Levenback CF, Gold MA, Fowler JM, Judson PL, et al. Is bilateral lymphadenectomy for midline squamous carcinoma of the vulva always necessary? An analysis from 
Gynecologic Oncology Group (GOG) 173. Gynecol Oncol. 2013;128:155-9.

68. Covens A, Vella ET, Kennedy EB, Reade CJ, Jimenez W, Le T. Sentinel lymph node biopsy in vulvar cancer: systematic review, meta-analysis and guideline recommendations. Gynecol Oncol. 2015;137:351-61.

69. Faries MB, Thompson JF, Cochran AJ, Andtbacka RH, Mozzillo N, Zager JS, et al. Completion dissection or observation for sentinel-node metastasis in melanoma. N Engl $\mathrm{J}$ Med. 2017;376:2211-22.

70. Leiter U, Stadler R, Mauch C, Hohenberger W, Brockmeyer NH, Berking C, et al. Final analysis of DeCOG-SLT trial: no survival benefit for complete lymph node dissection in patients with melanoma with positive sentinel node. J Clin Oncol. 2019;37:3000-8.

71. Huang J, Yu N, Wang X, Long X. Incidence of lower limb lymphedema after vulvar cancer: a systematic review and metaanalysis. Medicine (Baltimore). 2017;96:e8722.

72. Morton DL, Wanek L, Nizze JA, Elashoff RM, Wong JH. Improved long-term survival after lymphadenectomy of melanoma metastatic to regional nodes: analysis of prognostic factors in 1134 patients from the John Wayne Cancer Clinic. Ann Surg. 1991;214:491-9 (discussion 499-50).

73. Rao RD, Holtan SG, Ingle JN, Croghan GA, Kottschade LA, Creagan ET, et al. Combination of paclitaxel and carboplatin as second-line therapy for patients with metastatic melanoma. Cancer. 2006;106:375-82

74. Hodi FS, Soiffer RJ, Clark J, Finkelstein DM, Haluska FG. Phase II study of paclitaxel and carboplatin for malignant melanoma. Am J Clin Oncol. 2002;25:283-6.

75. Middleton MR, Grob JJ, Aaronson N, Fierlbeck G, Tilgen W, Seiter S, et al. Randomized phase III study of temozolomide versus dacarbazine in the treatment of patients with advanced metastatic malignant melanoma. J Clin Oncol. 2000;18:158-66.

76. Pasquali S, Hadjinicolaou AV, Chiarion Sileni V, Rossi CR, Mocellin S. Systemic treatments for metastatic cutaneous melanoma. Cochrane Database Syst Rev. 2018;2:CD011123.

77. Hodi FS, O'Day SJ, McDermott DF, Weber RW, Sosman JA, Haanen JB, et al. Improved survival with ipilimumab in patients with metastatic melanoma. N Engl J Med. 2010;363:711-23.

78. Wolchok JD, Chiarion-Sileni V, Gonzalez R, Rutkowski P, Grob J-J, Cowey CL, et al. Overall survival with combined nivolumab and ipilimumab in advanced melanoma. $\mathrm{N}$ Engl $\mathbf{J}$ Med. 2017;377:1345-56.

79. Robert C, Schachter J, Long GV, Arance A, Grob JJ, Mortier L, et al. Pembrolizumab versus ipilimumab in advanced melanoma. N Engl J Med. 2015;372:2521-32.

80. Robert C, Grange F, Mortier L, Karaszewska B, Rutkowski P, Mackiewicz A, et al. Improved overall survival in melanoma with combined dabrafenib and trametinib. N Engl J Med. 2015;372:30-9.

81. Topalian SL, Sznol M, McDermott DF, Kluger HM, Carvajal RD, Sharfman WH, et al. Survival, durable tumor remission, and long-term safety in patients with advanced melanoma receiving nivolumab. J Clin Oncol. 2014;32:1020-30.

82. Urba W, Martín-Algarra S, Callahan M, Wolchok J, Sharfman $\mathrm{W}$, Sosman J, et al. Immunomodulatory activity of nivolumab monotherapy in patients with advanced melanoma (abstract no. 2855). Presented at: American Associaction for Cancer Research Annual Meeting; 18-22 April 2015; Philadelphia (PA).

83. Robert C, Long GV, Brady B, Dutriaux C, Maio M, Mortier $\mathrm{L}$, et al. Nivolumab in previously untreated melanoma without BRAF mutation. N Engl J Med. 2015;372:320-30.

84. Weber JS, D’Angelo SP, Minor D, Hodi FS, Gutzmer R, Neyns B, et al. Nivolumab versus chemotherapy in patients with advanced melanoma who progressed after anti-CTLA-4 treatment
(CheckMate 037): a randomised, controlled, open-label, phase 3 trial. Lancet Oncol. 2015;16:375-84.

85. Postow MA, Chesney J, Pavlick AC, Robert C, Grossmann $\mathrm{K}$, McDermott D, et al. Nivolumab and ipilimumab versus ipilimumab in untreated melanoma. N Engl J Med. 2015;372:2006-17.

86. Larkin J, Chiarion-Sileni V, Gonzalez R, Grob JJ, Cowey CL, Lao $\mathrm{CD}$, et al. Combined nivolumab and ipilimumab or monotherapy in untreated melanoma. N Engl J Med. 2015;373:23-34.

87. D’Angelo SP, Larkin J, Sosman JA, Lebbé C, Brady B, Neyns B, et al. Efficacy and safety of nivolumab alone or in combination with ipilimumab in patients with mucosal melanoma: a pooled analysis. J Clin Oncol. 2017;35:226-35.

88. Ribas A, Hamid O, Daud A, Hodi FS, Wolchok JD, Kefford $\mathrm{R}$, et al. Association of pembrolizumab with tumor response and survival among patients with advanced melanoma. JAMA. 2016;315:1600.

89. Ribas A, Puzanov I, Dummer R, Schadendorf D, Hamid O, Robert $\mathrm{C}$, et al. Pembrolizumab versus investigator-choice chemotherapy for ipilimumab-refractory melanoma (KEYNOTE-002): a randomised, controlled, phase 2 trial. Lancet Oncol. 2015;16:908-18.

90. Hamid O, Robert C, Ribas A, Hodi FS, Walpole E, Daud A, et al. Antitumour activity of pembrolizumab in advanced mucosal melanoma: a post-hoc analysis of KEYNOTE-001, 002, 006. Br J Cancer. 2018;119:670-4.

91. Solinas C, Migliori E, De Silva P, Willard-Gallo K. LAG3: the biological processes that motivate targeting this immune checkpoint molecule in human cancer. Cancers (Basel). 2019;11:1213.

92. Wolf Y, Anderson AC, Kuchroo VK. TIM3 comes of age as an inhibitory receptor. Nat Rev Immunol. 2020;20:173-85.

93. Buchan SL, Rogel A, Al-Shamkhani A. The immunobiology of CD27 and OX40 and their potential as targets for cancer immunotherapy. Blood. 2018;131:39-48.

94. Ugurel S, Hildenbrand R, Zimpfer A, La Rosée P, Paschka P, Sucker A, et al. Lack of clinical efficacy of imatinib in metastatic melanoma. Br J Cancer. 2005;92:1398-405.

95. Wyman K, Atkins MB, Prieto V, Eton O, McDermott DF, Hubbard F, et al. Multicenter phase II trial of high-dose imatinib mesylate in metastatic melanoma. Cancer. 2006;106:2005-11.

96. Kim KB, Eton O, Davis DW, Frazier ML, McConkey DJ, Diwan $\mathrm{AH}$, et al. Phase II trial of imatinib mesylate in patients with metastatic melanoma. Br J Cancer. 2008;99:734-40.

97. Carvajal RD, Antonescu CR, Wolchok JD, Chapman PB, Roman R-A, Teitcher J, et al. KIT as a therapeutic target in metastatic melanoma. JAMA. 2011;305:2327-34.

98. Hodi FS, Corless CL, Giobbie-Hurder A, Fletcher JA, Zhu M, Marino-Enriquez A, et al. Imatinib for melanomas harboring mutationally activated or amplified KIT arising on mucosal, acral, and chronically sun-damaged skin. J Clin Oncol. 2013;31:3182-90.

99. Guo J, Si L, Kong Y, Flaherty KT, Xu X, Zhu Y, et al. Phase II, open-label, single-arm trial of imatinib mesylate in patients with metastatic melanoma harboring c-Kit mutation or amplification. J Clin Oncol. 2011;29:2904-9.

100. Carvajal RD, Lawrence DP, Weber JS, Gajewski TF, Gonzalez R, Lutzky J, et al. Phase II study of nilotinib in melanoma harboring KIT alterations following progression to prior KIT inhibition. Clin Cancer Res. 2015;21:2289-96.

101. Lee SJ, Kim TM, Kim YJ, Jang K, Lee HJ, Lee SN, et al. Phase II trial of nilotinib in patients with metastatic malignant melanoma harboring KIT gene aberration: a multicenter trial of Korean Cancer Study Group (UN10-06). Oncologist. 2015;20:1312-9.

102. Guo J, Carvajal RD, Dummer R, Hauschild A, Daud A, Bastian BC, et al. Efficacy and safety of nilotinib in patients with KIT-mutated metastatic or inoperable melanoma: final results 
from the global, single-arm, phase II TEAM trial. Ann Oncol. 2017;28:1380-7.

103. Cho JH, Kim KM, Kwon M, Kim JH, Lee J. Nilotinib in patients with metastatic melanoma harboring KIT gene aberration. Invest New Drugs. 2012;30:2008-14.

104. Delyon J, Chevret S, Jouary T, Dalac S, Dalle S, Guillot B, et al. STAT3 mediates nilotinib response in KIT-altered melanoma: a phase II multicenter trial of the French Skin Cancer Network. J Invest Dermatol. 2018;138:58-67.

105. Minor DR, Kashani-Sabet M, Garrido M, O'Day SJ, Hamid O, Bastian BC. Sunitinib therapy for melanoma patients with KIT mutations. Clin Cancer Res. 2012;18:1457-63.

106. Decoster L, Vande Broek I, Bart N, Françoise M, Baurain JF, Sylvie R, et al. Biomarker analysis in a phase II study of sunitinib in patients with advanced melanoma. Anticancer Res. 2015;35:6839-49.

107. Kluger HM, Dudek AZ, McCann C, Ritacco J, Southard N, Jilaveanu LB, et al. A phase 2 trial of dasatinib in advanced melanoma. Cancer. 2011;117:2202-8.

108. Kalinsky K, Lee S, Rubin KM, Lawrence DP, Iafrarte AJ, Borger DR, et al. A phase 2 trial of dasatinib in patients with locally advanced or stage IV mucosal, acral, or vulvovaginal melanoma: a trial of the ECOG-ACRIN Cancer Research Group (E2607). Cancer. 2017;123:2688-97.

109. Quintás-Cardama A, Lazar AJ, Woodman SE, Kim K, Ross M, Hwu P. Complete response of stage IV anal mucosal melanoma expressing KIT Val560Asp to the multikinase inhibitor sorafenib. Nat Clin Pract Oncol. 2008;5:737-40.

110. Seth R, Messersmith H, Kaur V, Kirkwood JM, Kudchadkar $\mathrm{R}$, McQuade JL, et al. Systemic therapy for melanoma: ASCO guideline. J Clin Oncol. 2020;38:3947-70.

111. Baetz TD, Fletcher GG, Knight G, McWhirter E, Rajagopal S, Song X, et al. Systemic adjuvant therapy for adult patients at high risk for recurrent melanoma: a systematic review. Cancer Treat Rev. 2020;87:102032.

112. Eggermont AMM, Blank CU, Mandala M, Long GV, Atkinson $\mathrm{V}$, Dalle S, et al. Adjuvant pembrolizumab versus placebo in resected stage III melanoma. N Engl J Med. 2018;378:1789-801.

113. Eggermont AMM, Chiarion-Sileni V, Grob J-J, Dummer R, Wolchok JD, Schmidt H, et al. Prolonged survival in stage III melanoma with ipilimumab adjuvant therapy. N Engl J Med. 2016;375:1845-55.

114. Weber J, Mandala M, Del Vecchio M, Gogas HJ, Arance $\mathrm{AM}$, Cowey CL, et al. Adjuvant nivolumab versus ipilimumab in resected stage III or IV melanoma. N Engl J Med. 2017;377:1824-35.

115. Edwards RH, Ward MR, Wu H, Medina CA, Brose MS, Volpe $\mathrm{P}$, et al. Absence of BRAF mutations in UV-protected mucosal melanomas. J Med Genet. 2004;41:270-2.

116. Cohen Y, Rosenbaum E, Begum S, Goldenberg D, Esche C, Lavie O, et al. Exon 15 BRAF mutations are uncommon in melanomas arising in nonsun-exposed sites. Clin Cancer Res. 2004;10:3444-7.

117. Wong CW. BRAF and NRAS mutations are uncommon in melanomas arising in diverse internal organs. J Clin Pathol. 2005;58:640-4.

118. Torres-Cabala CA, Wang W-L, Trent J, Yang D, Chen S, Galbincea J, et al. Correlation between KIT expression and KIT mutation in melanoma: a study of 173 cases with emphasis on the acral-lentiginous/mucosal type. Mod Pathol. 2009;22:1446-56.
119. Handolias D, Hamilton AL, Salemi R, Tan A, Moodie K, Kerr $\mathrm{L}$, et al. Clinical responses observed with imatinib or sorafenib in melanoma patients expressing mutations in KIT. Br J Cancer. 2010;102:1219-23.

120. Abu-Abed S, Pennell N, Petrella T, Wright F, Seth A, Hanna W. KIT gene mutations and patterns of protein expression in mucosal and acral melanoma. J Cutan Med Surg. 2012;16:135-42.

121. Aulmann S, Sinn HP, Penzel R, Gilks CB, Schott S, Hassel JC, et al. Comparison of molecular abnormalities in vulvar and vaginal melanomas. Mod Pathol. 2014;27:1386-93.

122. Pappa KI, Vlachos GD, Roubelakis M, Vlachos DEG, Kalafati TG, Loutradis D, et al. Low mutational burden of eight genes involved in the MAPK/ERK, PI3K/AKT, and GNAQ/11 pathways in female genital tract primary melanomas. Biomed Res Int. 2015. https://doi.org/10.1155/2015/303791.

123. Yélamos O, Merkel EA, Sholl LM, Zhang B, Amin SM, Lee $\mathrm{CY}$, et al. Nonoverlapping clinical and mutational patterns in melanomas from the female genital tract and atypical genital nevi. J Invest Dermatol. 2016;136:1858-65.

124. Udager AM, Frisch NK, Hong LJ, Stasenko M, Johnston CM, Liu JR, et al. Gynecologic melanomas: a clinicopathologic and molecular analysis. Gynecol Oncol. 2017;147:351-7.

125. Wylomanski S, Denis MG, Théoleyre S, Bouquin R, Vallée A, Knol AC, et al. BRAF mutations might be more common than supposed in vulvar melanomas. Exp Dermatol. 2018;27:210-3.

126. Shi K, Zhang B, Kong BY, Zhang Y, Igartua C, Mohan LS, et al. Distinct genomic features in a retrospective cohort of mucosal, acral and vulvovaginal melanomas. J Am Acad Dermatol. 2019. https://doi.org/10.1016/j.jaad.2019.07.017.

127. Virgili A, Zampino MR, Corazza M. Primary vulvar melanoma with satellite metastasis: dermoscopic findings. Dermatology. 2004;208:145-8.

128. de Giorgi V, Massi D, Salvini C, Mannone F, Cattaneo A, Carli P. Thin melanoma of the vulva: a clinical, dermoscopic-pathologic case study. Arch Dermatol. 2005;141:1046-7.

129. Lin J, Koga H, Takata M, Saida T. Dermoscopy of pigmented lesions on mucocutaneous junction and mucous membrane. Br J Dermatol. 2009;161:1255-61.

130. Debarbieux S, Ronger-Salve S, Dalle S, Balme B, Thomas L. Dermoscopy of desmoplastic melanoma: report of six cases. $\mathrm{Br}$ J Dermatol. 2008;159:360-3.

131. Rogers T, Pulitzer M, Marino ML, Marghoob AA, Zivanovic O, Marchetti MA. Early diagnosis of genital mucosal melanoma: how good are our dermoscopic criteria? Dermatol Pract Concept. 2016;6:43-6.

132. Blum A, Beck-Zoul U, Held L, Haase S. Dermoscopic appearance of an amelanotic mucosal melanoma. Dermatol Pract Concept. 2016;6:23-5.

133. Resende FS, Conforti C, Giuffrida R, de Barros MH, Zalaudek I. Raised vulvar lesions: be aware! Dermatol Pract Concept. 2018;8:158-61.

134. Theillac C, Cinotti E, Malvehy J, Ronger Savle S, Balme B, Robinson $\mathrm{P}$, et al. Evaluation of large clinically atypical vulvar pigmentation with RCM: atypical melanosis or early melanoma? J Eur Acad Dermatol Venereol. 2019;33:84-92.

135. Surveillance, Epidemiology, and End Results (SEER) Program, SEER*Stat Version 8.3.8: SEER 18 Registries, Nov 2019 Sub (2000-2017). https://seer.cancer.gov/seerstat/. Accessed 21 Dec 2020 . 